\title{
Erratum
}

\section{Altered white-matter architecture in treatment-naive adolescents with clinical depression - ERRATUM}

M. Aghajani, I. M. Veer, N. D. J. van Lang, P. H. F. Meens, B. G. van den Bulk, S. A. R. B. Rombouts, R. R. J. M. Vermeiren and N. J. van der Wee

doi: 10.1017/S0033291713003000. Published online by Cambridge University Press, 16 December 2013.

The publisher apologizes for an error found in the caption of Figure 1 in the recently published article by Aghajani et al. (2013).

On page 6, Figure 1, in the eighth and ninth lines of the Figure caption, FEW should be corrected to FWE.

\section{Reference}

Aghajani M, Veer IM, van Lang NDJ, Meens PHF, van den Bulk BG, Rombouts SARB, Vermeiren RRJM and van der Wee NJ. Altered white-matter architecture in treatment-naive adolescents with clinical depression. Psychological Medicine. Published online 16 December 2013, doi:10.1017/S0033291713003000. 